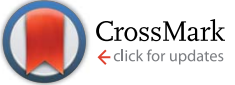

Cite this: RSC Adv., 2017, 7, 4339
Received 13th October 2016 Accepted 22nd December 2016

DOI: 10.1039/c6ra25167f

www.rsc.org/advances

\section{Biodemulsifiers produced by Achromobacter sp. and their features in improving the biodegradation of phenanthrene $\uparrow$}

\author{
Chunyan Li, Tingting Jia, Meng Fu, Ning Hou, ${ }^{*}$ Huiming Cao, Qiaoruo Wang \\ and Dapeng Li
}

\begin{abstract}
The application of biodemulsifiers plays an essential role in oil recovery and demulsification. However, little is known about their features during the biodegradation of petroleum hydrocarbons. In the present study, a demulsifying strain of Achromobacter sp. LH-1 was applied for the degradation of petroleum hydrocarbons and the effects of the biodemulsifiers produced by $\mathrm{LH}-1$ during the degradation process were investigated. Several common petroleum hydrocarbons, including aromatic and aliphatic compounds, were utilized by strain LH-1 as the sole carbon source for the production of biodemulsifiers. Taking phenanthrene (PHE) as the sole carbon source with an initial concentration of $100 \mathrm{mg} \mathrm{L}^{-1}$, the optimal cultivation conditions were determined using response surface methodology based on a BoxBehnken design to further enhance demulsification efficiency. The results showed that $\mathrm{LH}-1$ could secret lipopeptide extracellular biodemulsifiers and achieved 95.6\% demulsification efficiency for water-in-oil model emulsions within $24 \mathrm{~h}$ and $92.3 \%$ PHE degradation efficiency within five days. It demonstrated that biodemulsifier-induced dissolution played the dominant role in PHE degradation and thus, the excellent PHE degradation capability of LH-1 is closely related to biodemulsifier production.
\end{abstract}

\section{Introduction}

Annually, the petrochemical, smelting, chemical, and mineral industries produce large amounts of emulsified wastewater, leading to serious environmental pollution. Petroleum-field emulsions are also associated with problems such as poisoning of catalysts, higher transport and storage costs, deposits of salt in the refining equipment and corrosion. ${ }^{1}$ Biodemulsifiers exhibit excellent surface activities and high efficiency in breaking oil-inwater $(\mathrm{O} / \mathrm{W})$ and water-in-oil (W/O) emulsions. Recently developed biodemulsifiers have attracted a great deal of attention because of their potential application in breaking down emulsions. Compared with chemical demulsifiers, biodemulsifiers generally exhibit greater environmental compatibility, lower toxicity, higher biodegradability, and better functionality under extreme conditions. Therefore, biodemulsifiers appear to be better candidates for extracting crude petroleum and bioremediating oil contaminated soils. ${ }^{2-5}$ Some studies have focused on screening and characterizing biodemulsifier producing bacteria by evaluating their demulsifying capacity and optimizing their incubation conditions, whereas others have focused on the physicochemical properties, isolation, or compositions of the biodemulsifiers produced by the

College of Resources and Environment, Northeast Agricultural University, Harbin 150030, China. E-mail: houning571@163.com; Tel: +8645155190034

$\dagger$ Electronic supplementary information (ESI) available. See DOI: $10.1039 / \mathrm{c} 6 \mathrm{ra} 25167 \mathrm{f}$ bacteria. ${ }^{\mathbf{1 , 6 - 8}}$ Component analysis of biodemulsifiers is particularly useful to further understand their demulsifying properties and possible industrial applications. Therefore, it is important to investigate the physicochemical properties and effective components of biodemulsifiers. However, the complexity of biodemulsifier components complicates their study.

Despite their numerous advantages over synthetic chemical demulsifiers, the economic competitiveness of biodemulsifiers is restricted because of problems related to large-scale, cheap production and limited applications. ${ }^{9}$ The economic production of biodemulsifiers might be achieved by using a cheap carbon source,${ }^{10}$ including agriculture wastes such as lactic whey, ${ }^{11}$ potato processing effluent, ${ }^{12}$ straw, ${ }^{13}$ cashew apple juice ${ }^{\mathbf{1 4}}$ or waste oils from the catering and food industries. ${ }^{15-17}$ Among these substrates, waste oils have been studied as an alternative substrate. However, the ability of bacteria to utilize toxic environmental pollutants as their sole carbon source to produce biodemulsifiers has not been studied. Every year, a high concentration of petroleum hydrocarbons are generated during the extraction and processing of oil and gas fuels ${ }^{\mathbf{1 8}}$ and these toxic hydrocarbons are present in oil contaminated soil, and their discharge into the environment causes extensive environmental (surface water, ground water, marine water) contamination. ${ }^{\mathbf{1 9}}$ Therefore, petroleum hydrocarbons must to be eliminated before discharge to the environment or recycling. Polycyclic aromatic hydrocarbons (PAHs), as a component of petroleum hydrocarbons, are listed as priority pollutants by the United States 
Environmental Protection Agency (EPA)., ${ }^{\mathbf{2 0} 21}$ The hydrophobicity and low aqueous solubility of most PAHs limits the rate of PAH biodegradation in the environment. ${ }^{22}$ Biodemulsifiers, which possess both hydrophobic and hydrophilic moieties, tend to reduce the surface and interfacial tension of solutions. This feature might increase the solubilization of hydrocarbons and subsequently enhance their biodegradability. Consequently, biodemulsifiers have excellent surface activity and have been widely applied in many industrial fields. ${ }^{23}$ Thus, the use of biodemulsifiers might be an effective microbial strategy to influence the bioavailability of PAHs and other petroleum hydrocarbons. Therefore, bacteria with the ability to degrade petroleum hydrocarbons while also producing a biodemulsifier to prevent inhibition of biodegradation are highly desirable for the rapid degradation of petroleum hydrocarbons. However, as far as is known, there are no reports focused on this subject.

Phenanthrene (PHE), a model PAH, is composed of three benzene rings and is one of the 16PAHs listed as a priority hazardous contaminants by the US EPA. ${ }^{24}$ In addition, PHE has also been tested as a model compound for studying microbial transformation and the degradation of $\mathrm{PAH}^{25}$ and for isolating novel PAH-degrading bacteria. ${ }^{26}$

The aims of the present study were: (1) to study the biodemulsification efficiency of Achromobacter sp. LH-1 (LH-1) using PHE as sole carbon source, and optimize conditions to achieve higher demulsification efficiency using response surface methodology (RSM), (2) to determine the demulsification efficiency of LH-1 for petroleum hydrocarbons including various aromatic compounds and aliphatic compounds, (3) to characterize the properties of the biodemulsifiers produced by $\mathrm{LH}-1$, which can use PHE as the sole carbon source, and (4) to explore the effects of biodemulsifiers on the biodegradation of PHE.

\section{Material and methods}

\subsection{Cultivation of demulsifying bacteria}

In this study, the biodemulsifier producing microorganism Achromobacter sp. LH-1 (Accession no. KF880996) was used in the laboratory and PAH degradation tests. This strain was isolated from crude oil contaminated soil and stored in our laboratory. Preliminary experiments revealed that the biodemulsifier produced by strain $\mathrm{LH}-1$ is an effective biodemulsifier and that $\mathrm{LH}$ 1 can also utilize many types of aromatic compounds for growth.

The mineral salt medium (MSM) used contained the following: $0.2 \mathrm{~g}$ of $\mathrm{MgSO}_{4} \cdot 7 \mathrm{H}_{2} \mathrm{O}, 0.02 \mathrm{~g}$ of $\mathrm{CaCl}_{2}, 1.0 \mathrm{~g}$ of $\mathrm{KH}_{2} \mathrm{PO}_{4}$, $1.0 \mathrm{~g}$ of $\mathrm{K}_{2} \mathrm{HPO}_{4}, 1.0 \mathrm{~g}$ of $\mathrm{NH}_{4} \mathrm{NO}_{3}$, and $0.05 \mathrm{~g}$ of $\mathrm{FeCl}_{3}$, adjusted to $\mathrm{pH}$ 7.0. PHE was dissolved in acetone and added to the sterile medium at a final concentration of $100 \mathrm{mg} \mathrm{L^{-1 }}$. The solid MSM contained $20.0 \mathrm{~g}$ of agar per liter. Solid Luria Bertani medium was used to store the bacteria and included $10.0 \mathrm{~g}$ of $\mathrm{NaCl}, 10.0 \mathrm{~g}$ of peptone, $5.0 \mathrm{~g}$ of yeast extract, and $20.0 \mathrm{~g}$ agar per liter.

\subsection{Chemicals and solvents}

Analytical grade PHE, naphthrene, fluoranthene, and pyrene were purchased from Sigma-Aldrich (St. Louis, MO, USA). All solvents were HPLC grade.

\subsection{Biodegradation of PHE and evaluation of demulsifying capability}

In the PHE biodegradation tests, residual PHE in the cultures was extracted twice with hexane $(\mathrm{v} / \mathrm{v})$, and the extracts were dried using anhydrous $\mathrm{Na}_{2} \mathrm{SO}_{4}$. The residual PHE in the extracts was determined using gas chromatography (GC) with a Shimadzu GC2014 gas chromatograph equipped with a flame ionization detector (FID) and a fused silica chromatographic column packed with $14 \%$ OV-1701 $(30 \mathrm{~m} \times 0.53 \mathrm{~mm} \times 1.0 \mu \mathrm{m})$. The GC conditions were as follows: $1 \mu \mathrm{L}$ of sample was injected with a split ratio of $17: 1$, the column temperature was maintained at $180{ }^{\circ} \mathrm{C}$, and the detector and injector temperatures were maintained at $240{ }^{\circ} \mathrm{C}$ and $220{ }^{\circ} \mathrm{C}$, respectively. Nitrogen was supplied as the carrier gas at a flow rate of $3.0 \mathrm{~mL} \mathrm{~min}^{-1}$. The experiment was repeated three times and control tests were performed with the PHE supplemented medium without inoculation.

To prepare the $\mathrm{W} / \mathrm{O}$ emulsion, ${ }^{27}$ distilled water (containing $1.9 \% \mathrm{w} / \mathrm{v}$ Span 80 ) and kerosene (containing $0.1 \% \mathrm{w} / \mathrm{v}$ Tween 80 ) were mixed at a ratio of $3: 2(\mathrm{v} / \mathrm{v})$ at $10000 \mathrm{rpm}$ for $3.5 \mathrm{~min}$ in a high speed emulsifying machine. The emulsion type was verified using the Oil Red $\mathrm{O}$ test described by Lee and Lee. ${ }^{28}$ The prepared emulsion was very stable, with an oil separation ratio of $<2 \%$ at $30{ }^{\circ} \mathrm{C}$ within $24 \mathrm{~h}$.

In the demulsification test, $1 \mathrm{~mL}$ of whole culture was incubated for five days and then added to a $10 \mathrm{~mL}$ graduated test tube containing $5 \mathrm{~mL}$ of $\mathrm{W} / \mathrm{O}-$ model emulsion. The tube was shaken 50 times to mix the contents thoroughly and then placed in an incubator at $30{ }^{\circ} \mathrm{C}$. The volume of emulsion remaining was recorded at certain time intervals. The same amount of sterile culture medium was used as a blank control. The blank control, with $1 \mathrm{~mL}$ of sterile culture medium, had a demulsification efficiency of $<5 \%$ within $24 \mathrm{~h}$ for the W/O emulsion model. The demulsification efficiency of the bacteria after five days of incubation was calculated from the following equation:

Demulsification rate $=$

$$
\left(1-\frac{\text { remaining emulsion volume }}{\text { original emulsion volume }+ \text { added culture }}\right) \times 100 \%
$$

A bacterium that exhibited a demulsification efficiency of greater than $80 \%$ in the demulsification test was considered to have demulsification capability. ${ }^{29}$

\subsection{Experimental design for optimizing the demulsification conditions of the strain}

Response surface methodology (RSM) is a valuable tool that has been widely applied in engineering processes for optimization purposes. ${ }^{30}$ Using this methodology, optimal conditions can be identified while minimizing the number of experiments required for a selected response. In this study, the statistical software Design Expert 8.0 (Stat-Ease, Inc.) was employed for the analysis. Four primary factors that may have an effect on demulsification efficiency in the W/O-model emulsion are: temperature, $\mathrm{pH}$, substrate concentration and inoculum size. The selection of three independent variables and their levels 
were based on a preliminary single factor experiment. Demulsification efficiency was the response variable. The experimental ranges and levels of the independent variables for demulsification are illustrated in Table S1 (ESI $\dagger$ ). To confirm the predicted results of the optimized model, the demulsification efficiency was tested in triplicate under the optimized reaction conditions.

\subsection{Utilization of other carbon sources}

In addition to PHE, the demulsification efficiency of the strain was also evaluated on other carbon sources at concentrations of $100 \mathrm{mg} \mathrm{L}^{-1}$. More than ten carbon sources were tested as carbon substrates for LH-1, including various low molecular weight and high molecular weight PAHs (naphthrene, fluoranthene, and pyrene), monoaromatic hydrocarbons (benzene, toluene and xylene) and intermediates of PHE degradation (catechol and salicylic acid). These substrates were added to the sterilized liquid medium as the sole carbon source. The growth test of LH-1 incubated for five days in different carbon sources was followed by measuring the increase in the optical density $\left(\mathrm{OD}_{600}\right)$ of the medium. ${ }^{31,32} \mathrm{An}$ identical volume of sterile culture medium without bacteria was incubated under similar conditions as a blank control. Furthermore, to evaluate the effects of different carbon sources on the demulsification efficiency of $\mathrm{LH}-1$, the bacteria were incubated in MSM medium for two days and supplemented with $4 \%(\mathrm{v} / \mathrm{v})$ aliphatic compounds, including liquid paraffin, $n$-hexadecane, and waste frying oil. The waste frying oil used in this study was obtained from restaurant soybean oil and lard, which were filtered to remove the dregs. The lard was composed of various unsaturated fatty acid chains of different lengths and saturation levels, including linoleic acid $\left(\mathrm{C}_{18}: 2\right)$, oleic acid $\left(\mathrm{C}_{18}: 1\right)$, and stearic acid $\left(\mathrm{C}_{18}: 0\right)$. The soybean oil was composed of saturated and unsaturated acids with various carbon chain lengths and most of these acids were $\mathrm{C}_{16}-\mathrm{C}_{18}$ unsaturated acids. An identical volume of sterile culture medium without bacteria was incubated under similar conditions as a blank control.

\subsection{Purification and preliminary identification of the biodemulsifier produced by strain LH-1}

Solvent extraction was employed as the first step to purify crude biodemulsifiers. Chloroform-methanol ( $2: 1, \mathrm{v} / \mathrm{v})$ was used as the extraction solvent because the amount of recovered precipitate obtained with this solvent was higher compared to other organic solvents. The crude biodemulsifiers were further purified using column chromatography. The crude material was dissolved in methanol $\left(1 \mathrm{mg} \mathrm{mL} \mathrm{m}^{-1}\right)$ and passed through a silica gel column (200-300 mesh), as described by Huang et al. ${ }^{27}$ The

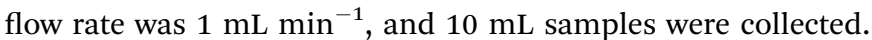
The solvents from the active fractions containing biodemulsifiers were evaporated to dryness. The demulsification efficiency of the samples for the W/O-model emulsions were then determined, followed by analysis using thin-layer chromatography (TLC) and Fourier transform-infrared spectroscopy using a Bruker ALPHA-T FTIR spectrometer (FTIR). TLC of the purified biodemulsifier was performed to detect the effective demulsifier component using various developing solvent systems, including chloroform-ethanol (95: $5 \mathrm{v} / \mathrm{v}$ ), chloroformethanol-water (85:15:2 v/v), chloroform-ethanol-water (65: $25: 4 \mathrm{v} / \mathrm{v})$, hexane-ethanol-acetic acid (85:15:2 v/v), and $n$-butanol-formic acid-water $(16: 4: 8 \mathrm{v} / \mathrm{v})$, as described by Kuyukina et $a l .{ }^{33}$ The best performance was achieved with chloroform-ethanol-water (65: $25: 4 \mathrm{v} / \mathrm{v}$ ). Ninhydrin, bromothymol blue, and phenol-sulfuric acid were used as developing agents, as recommended by Cooper et al. ${ }^{34}$ FTIR was the most useful method for identifying the main functional chemical groups present on the biodemulsifier that are responsible for the demulsification efficiency for the W/O-model emulsion. A portion (1 $\mathrm{mg}$ ) of freeze dried and completely purified biodemulsifier was mixed with $100 \mathrm{mg}$ of potassium bromide $(\mathrm{KBr})$ and pressed for $30 \mathrm{~s}$ to obtain a translucent pellet. Infrared absorption spectra were recorded on the FTIR spectrometer. A blank $\mathrm{KBr}$ pellet was used as the background reference.

\subsection{PHE solubilization assay}

PHE solubilization assays were performed as previously described..$^{35}$ Briefly, $60 \mu \mathrm{g}$ of PHE (from a $6 \mathrm{mg} \mathrm{mL}{ }^{-1}$ stock in hexane) was distributed into glass test tubes $(10 \times 170 \mathrm{~mm})$ and left open inside a chemical fume hood to remove the solvent. Then, $3.0 \mathrm{~mL}$ of assay buffer $\left(20 \mathrm{mmol} \mathrm{L}^{-1}\right.$ Tris-HCl, pH 7.0) and increasing concentrations of the biodemulsifier were added to the tubes. The tubes were capped with plastic closures and incubated in a vertical position overnight at $30^{\circ} \mathrm{C}$ with shaking at $150 \mathrm{rpm}$ in the dark. The samples were filtered through a 1.2 $\mu \mathrm{m}$ pore size filter, and $2 \mathrm{~mL}$ of this filtrate was extracted with an equal volume of hexane. The aqueous and hexane phases were separated via centrifugation at $10000 \mathrm{~g}$ for $2 \mathrm{~min}$. The PHE in the hexane extracts was measured spectrophotometrically at $254 \mathrm{~nm}$, and the concentration of PHE was determined using a calibration curve of PHE in hexane. Control experiments in which no biodemulsifier was added to PHE prior to extraction with hexane were performed in parallel.

\subsection{Analytical methods}

All the experiments, including the controls, were repeated three to five times. The data shown in the corresponding figures and tables represent mean values, with error bars representing standard deviation.

\section{Results and discussion}

\subsection{PHE degradation and demulsification capability of LH-1}

The efficiency of strain LH-1 for PHE degradation and demulsification for the W/O-model emulsion after five days incubation in the liquid cultures was investigated. As shown in Fig. 1, more than $92 \%$ of PHE was degraded by $\mathrm{LH}-1$ at an initial concentration of $100 \mathrm{mg} \mathrm{L}^{-1}$. As shown in Fig. 2, strain LH-1 achieved more than $70 \%$ demulsification efficiency within $12 \mathrm{~h}$, and a significantly higher demulsification efficiency (93.5\%) was achieved after $24 \mathrm{~h}$ incubation, suggesting the excellent capacity of LH-1 for biodemulsifier production. 


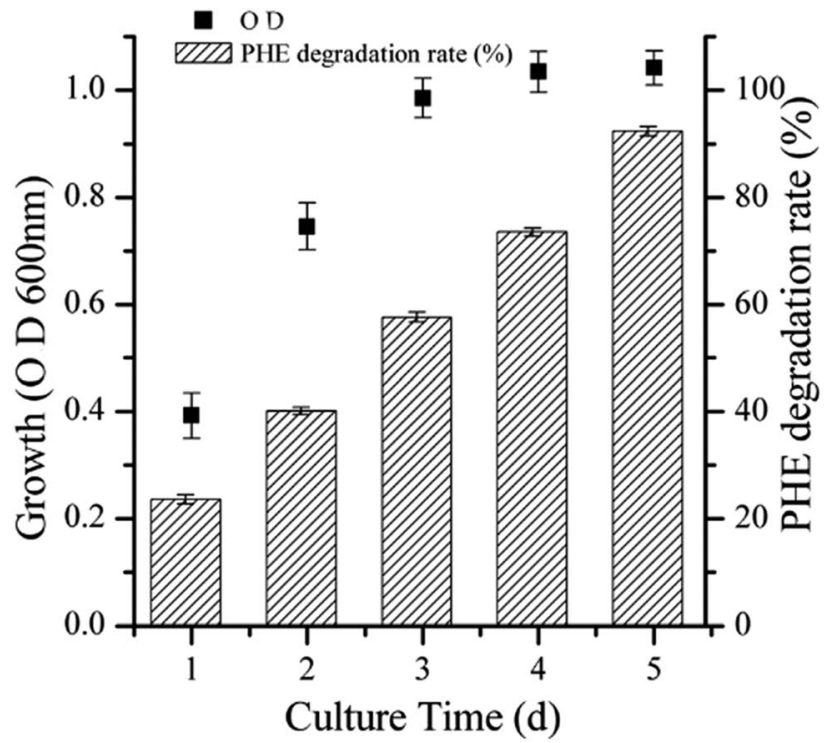

Fig. 1 Demulsification curve of LH-1. The LH-1 strain was cultured in MSM (containing $100 \mathrm{mg} \mathrm{L}^{-1} \mathrm{PHE}$ ) medium for $24 \mathrm{~h}$. Demulsification assays were performed at $30{ }^{\circ} \mathrm{C}$. Each value is expressed as the average of triplicate observations, and the bars represent standard deviation.

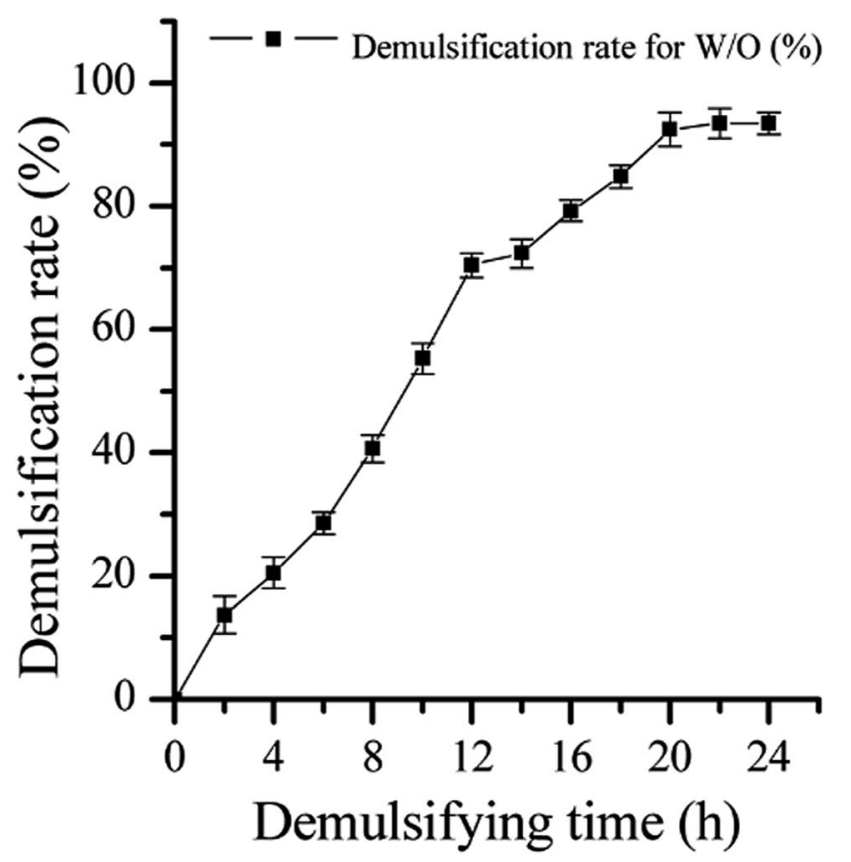

Fig. 2 Growth rate and demulsification efficiency of LH-1 grown under various culture conditions. Each datum represents the average of triplicate observations, and the bars represent standard deviation.

\subsection{Optimization of demulsification culture conditions using RSM}

Box-Behnken design (BBD). Because of the excellent performance of LH-1 in terms of demulsification of W/O-model emulsions, a subsequent investigation was performed to optimize its cultivation conditions for demulsification using a three level BBD and improve its demulsification efficiency. Table S2 (ESI $\dagger$ ) shows the experimental design and results for the demulsification obtained using RSM optimization. The demulsification efficiency for the $\mathrm{W} / \mathrm{O}$ model emulsions ranged from $50.68 \%$ to $96.94 \%$. The minimum demulsification efficiency for the $\mathrm{W} / \mathrm{O}$ model emulsions was achieved at $\mathrm{pH} 8$, with an inoculum size of $4 \%$, a temperature of $33^{\circ} \mathrm{C}$, and a substrate concentration of $125 \mathrm{mg} \mathrm{L}^{-1}$. The maximum demulsification efficiency was achieved at $\mathrm{pH} 7$, with an inoculum size of $4 \%$, a temperature of $33{ }^{\circ} \mathrm{C}$, and a substrate concentration of $100 \mathrm{mg}$ $\mathrm{L}^{-1}$. Multiple regression analysis of the experimental data yielded the following second-order polynomial equation for the predicted response $Y_{1}$, which represents the demulsification efficiency for the W/O model emulsion: ${ }^{36-38}$

$$
\begin{aligned}
Y_{1}= & 96.06-1.33 A-7.33 B+1.21 C-1.04 D+2.13 A B \\
& +1.43 A C-2.26 A D-1.66 B C-0.80 B D-1.39 C D \\
& -5.80 A^{2}-26.53 B^{2}-11.36 C^{2}-3.88 D^{2}
\end{aligned}
$$

The accuracy of the model was evaluated using the coefficient of determination $\left(R^{2}\right)$, which was 0.9961 . An analysis of variance (Table S3, ESI $\dagger$ ) also indicated that both of the regression models were statistically acceptable $(p<0.0001)$ and that the model had no significant $(p>0.05)$ lack of fit. Additionally, the values of the previously mentioned indicators were similar to those reported by Li et al. and Xu et al. ${ }^{\mathbf{3 9 , 4 0}}$ The regression analysis for demulsification indicated that $A, B$, $C, D, A B, A C, A D, B C, C D, A^{2}, B^{2}, C^{2}$ and $D^{2}$ were significant terms for the demulsification efficiency of LH-1 $(p<0.05) .{ }^{\mathbf{4 0 , 4 1}}$ Among the variables, the $p$-values for temperature, substrate concentration, and $\mathrm{pH}$ were less than 0.01 , thus, these three factors significantly impact on the demulsification efficiency. The values of $P_{A B}, P_{A C}, P_{A D}, P_{B C}$ and $P_{C D}(0.0043,0.0376,0.0028$, 0.0187 and 0.0438 , respectively) indicated that the interaction effects between temperature and substrate concentration, temperature and $\mathrm{pH}$, temperature and inoculum size, substrate concentration and $\mathrm{pH}$, and $\mathrm{pH}$ and inoculum size were also highly significant. The predicted coefficient $\left(R^{2}\right.$ pred.) of 0.9792 was in reasonable agreement with the adjusted coefficient ( $R^{2}$ adj.) of $0.9923 .^{38}$ The small difference between $R^{2}$ pred. and $R^{2}$ adj. indicated that the regression model accurately accounted for the relationship between the observed and predicted values.

Analysis of the response surface. To evaluate the impact of the interactions between the independent variables on the demulsification efficiency of the LH-1 strain for the W/O model emulsion, a three-dimensional mesh was used. Fig. 3a shows how the interactions between temperature and substrate concentration affected the demulsification efficiency for the W/O-model emulsion. When $\mathrm{pH}$ and inoculum size were maintained at central levels, the demulsification efficiency of the LH-1 cultures initially increased and subsequently decreased as the substrate concentration increased. A demulsification efficiency of $>85 \%$ was observed for $\mathrm{LH}-1$ cultures incubated at temperatures of $33.6{ }^{\circ} \mathrm{C}$ to $34.2{ }^{\circ} \mathrm{C}$ with substrate concentrations of $101 \mathrm{mg} \mathrm{L}^{-1}$ to $103 \mathrm{mg} \mathrm{L}^{-1}$. Fig. 3b 

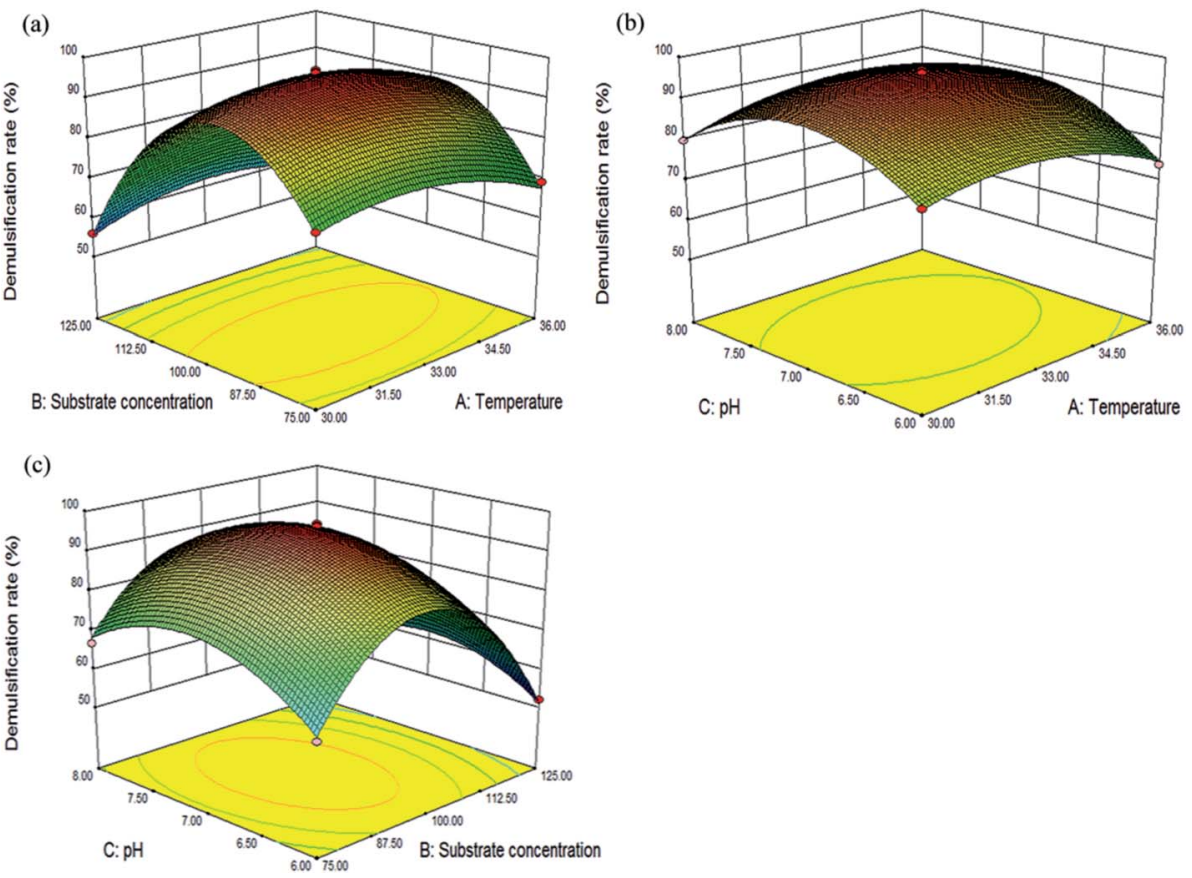

Fig. 3 Three-dimensional surface plot of RSMs for the demulsification efficiency of LH-1. (a) The interaction effect of temperature and substrate concentration on the demulsification efficiency of $\mathrm{LH}-1$; (b) the interaction effect of temperature and $\mathrm{pH}$ on the demulsification efficiency of $\mathrm{LH}$ 1; (c) the interaction effect of substrate concentration and $\mathrm{pH}$ on the demulsification efficiency of LH-1.

illustrates how interactions between temperature and $\mathrm{pH}$ affected the demulsification efficiency for the W/O model emulsion. When the substrate concentration and inoculum size were maintained at median levels, a high demulsification efficiency for the W/O model emulsion was obtained when incubated at $\mathrm{pH}$ values between 7.1 and 7.3 and temperatures between $33.2{ }^{\circ} \mathrm{C}$ and $33.8^{\circ} \mathrm{C}$. However, a low demulsification efficiency was observed at $\mathrm{pH}>7.5$ and temperatures exceeding $34{ }^{\circ} \mathrm{C}$. Fig. 3c depicts how interactions between substrate concentration and $\mathrm{pH}$ affected the demulsification efficiency for the W/O model emulsion. The response surface, which exhibits an opening downward trend, indicates that an increase in each variable enhanced the demulsification efficiency. The highest response value was obtained when the culture $\mathrm{pH}$ was 7.2 and the substrate concentration was $101.8 \mathrm{mg} \mathrm{L}^{-1}$. The $\mathrm{pH}$ and the substrate concentration response surface were steeper than the response surface for other variable combinations, illustrating that, of the interactions evaluated, the interaction between $\mathrm{pH}$ and substrate concentration had the most significant effect on demulsification efficiency for the $\mathrm{W} / \mathrm{O}$ model emulsion. These results indicate that when each factor is set to a fixed value of zero, the highest demulsification efficiency for the $\mathrm{W} / \mathrm{O}$ model emulsion is located in the central area of the response surface and that the extreme value point is also situated in this region. Thus, using the Design Expert 8.0 software package it was determined that the optimal values of the response surface for optimal demulsification conditions for LH-1 cultures were a cultivation temperature of $33.26^{\circ} \mathrm{C}$, a pH of 7.23 , a substrate concentration of $101.49 \mathrm{mg} \mathrm{L}^{-1}$, and an inoculum size of $4.08 \%$.

\subsection{Demulsification efficiency of LH-1 for various aromatic compounds and aliphatic compounds}

As shown in Fig. 4, the demulsification efficiency of LH-1 for the W/O model emulsion exhibited the following order: PHE > naphthrene $>$ fluoranthene $>$ salicylic acid $>$ catechol $>$ benzene $>$ pyrene $>$ xylene $>$ toluene. For PHE, naphthrene or fluoranthene as the sole carbon source, LH-1 exhibited a greater demulsification efficiency for the $\mathrm{W} / \mathrm{O}$ model emulsion $(92.5 \%$, $80.4 \%$ and $71.6 \%$, respectively). However, LH-1 exhibited relatively low demulsification efficiency (no greater than 30\%) for the W/O model emulsion with benzene, salicylic acid or catechol as the sole carbon source. In other words, the demulsifying substance produced under these conditions exhibited very low demulsification efficiency. These results suggest that the types or quantities of biodemulsifiers synthesized by the LH-1 strain utilized different types of carbon sources. Thus, it was speculated that the biodemulsifier produced by LH-1 is composed of synthesized secondary metabolites rather than the cells themselves. The LH-1 strain utilizes different types of substrates as the carbon source, possibly via different metabolic pathways that produce diverse metabolites and enzymes. Furthermore, when LH-1 utilized toluene, xylene or pyrene as the sole carbon source, almost no demulsification was observed for the $\mathrm{W} / \mathrm{O}$ model emulsion, possibly because LH-1 is less able to use toluene, xylene or pyrene as the sole carbon source for growth.

As shown in Table S4 (ESI $\dagger$ ), LH-1 exhibited a high demulsification efficiency for the W/O model emulsion when cultured with aliphatic compounds. More specifically, liquid paraffin cultures achieved $96.3 \%$ demulsification efficiency, waste frying oil cultures achieved 93.4\% demulsification efficiency, and $n$ - 


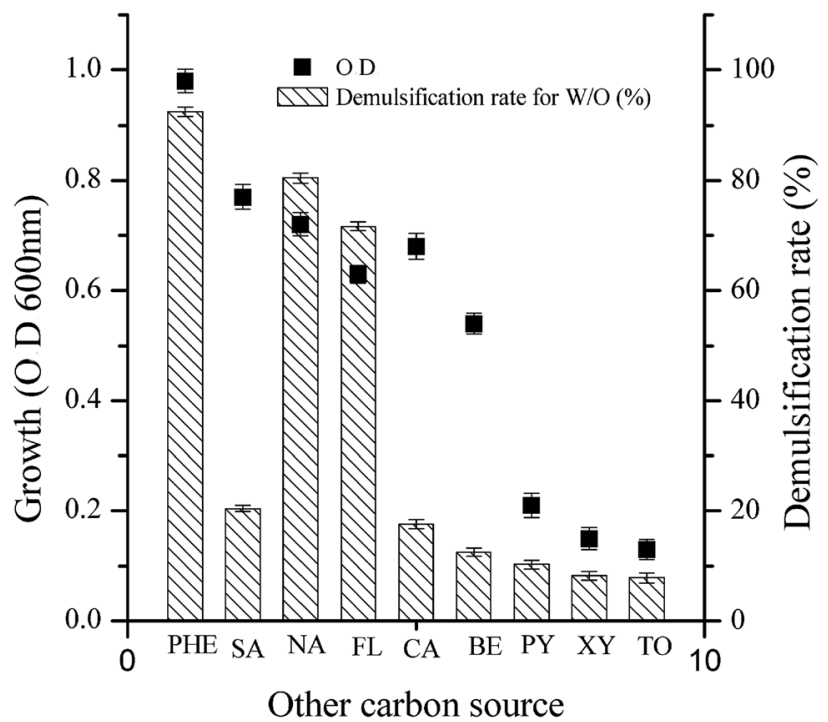

Fig. 4 Demulsification rate of LH-1 grown on various carbon sources. The carbon sources included phenanthrene (PHE), naphthrene (NA), pyrene (PY), catechol (CA), fluoranthene (FL), salicylic acid (SA), benzene (BE), toluene (TO), and xylene (XY). Each value is expressed as the average of triplicate observations, and the bars represent standard deviation.

hexadecane cultures achieved $83.2 \%$ demulsification efficiency within $24 \mathrm{~h}$. The LH-1 strain exhibited the greatest demulsification efficiency when liquid paraffin was used as the primary carbon source. Liquid paraffin is relatively simple and easy to utilize by the demulsifying bacteria, thus, it is typically used as the carbon source to culture biodemulsifier producing bacteria. ${ }^{29} \mathrm{~A}$ high demulsification efficiency for $\mathrm{W} / \mathrm{O}$ model emulsions was also obtained when using waste frying oil, which is composed of various unsaturated fatty acid chains of different lengths and saturation levels, including linoleic acid $\left(\mathrm{C}_{18}: 2\right)$, oleic acid $\left(\mathrm{C}_{18}: 1\right)$, and stearic acid $\left(\mathrm{C}_{18}: 0\right) \cdot{ }^{42-44}$ This result indicates that LH-1 preferentially utilizes $\mathrm{C}_{18}$ fatty acid chains during biodemulsifier synthesis. ${ }^{29}$ A simple straight-chain alkane, $n$-hexadecane, was also a good carbon source for LH-1.

The results mentioned previously, suggest that the LH-1 strain exhibits reasonable demulsification efficiency for $\mathrm{W} / \mathrm{O}$ model emulsions when cultured with aromatic compounds or aliphatic compounds as the sole carbon source. However, the LH-1 strain exhibited a higher demulsification efficiency when simple aliphatic compounds were used as the carbon source rather than complex aromatic compounds. Bacterial growth and metabolism may be restricted when aromatic compounds are used as the sole carbon source by LH-1 because more complicated degradation processes are required than those needed for simpler molecules (aromatic compounds).

\subsection{Preliminary evaluation of the effective component of the demulsifiers produced by $\mathbf{L H}-1$}

The demulsification efficiency of the suspended cells and cell free cultures produced by LH-1 after five days cultivation were tested using the $\mathrm{W} / \mathrm{O}$ model emulsion. The demulsification efficiency of the suspended cells $(11.5 \%)$ was lower than that of the cell free culture after $24 \mathrm{~h}$ of observation. The results suggested that the primary effective demulsification components of LH-1 were derived from extracellular metabolites rather than cellular matter. Similar results had been observed for other demulsifying microbes. ${ }^{45}$ The characteristics of the biodemulsifier produced by LH-1 were then evaluated using several tests, including temperature and chemical processing methods. As shown in Table 1, neither the high temperature processing nor the freeze-thawing treatment affected the demulsification efficiency. It is well known that high temperatures could damage the stereo-conformations and the active sites of proteins and thus affect their enzymatic activity, ${ }^{46}$ therefore, it could be inferred that the effective demulsification components of LH-1 were not proteins. Proteinase K, a serine proteinase with cleavage activity, could cleave the carboxyl terminal peptide bonds of aliphatic and aromatic amino acids. Proteinase E is a type of mixed protease without a specific functional site. Pectinase could decompose pectin, which is an acidic polysaccharide substance. Lipase is an ester bond hydrolytic enzyme that could generate glycerol and fatty acids. The effects of pectinase, proteinase $\mathrm{K}$, proteinase $\mathrm{E}$ and lipase on demulsification efficiency are shown in Table 1. After treatment with pectinase, the demulsification efficiency was unchanged for the W/O model emulsion (94.1\%), indicating that the effective components of the biodemulsifiers were not polysaccharide substances. A remarkable decrease was detected on the demulsification efficiency of LH-1 cell free cultures for the W/O model emulsions after treatment with proteinase $\mathrm{K}$ and proteinase E. This phenomenon could be explained by the fact that proteinase $\mathrm{K}$ and proteinase $\mathrm{E}$ are able to hydrolyze peptide bonds, although the specificity is not strong. Lipopeptides contain peptide bonds, suggesting that the structure of a lipopeptide was being damaged by proteinase $\mathrm{K}^{47}$ Lipopeptides could also contain ester groups and aliphatic chains, and lipases could hydrolyze ester bonds. These results suggested that the primary effective demulsification components of LH-1 may be lipopeptides.

After solvent extraction with chloroform-methanol $(2: 1, \mathrm{v} /$ v), the crude biodemulsifiers secreted by LH-1 exhibited a high demulsification efficiency for the W/O model emulsion (94\%). The crude biodemulsifiers were then further purified using column chromatography on a silica gel column. The purified biodemulsifier obtained from the silica gel column had

Table 1 Effect of enzyme treatment on the demulsifying efficiencies of crude biodemulsifiers for the W/O model emulsion

\begin{tabular}{ll}
\hline Treatment modes & Demulsification \\
\hline Blank control & $93.8 \% \pm 0.2 \%$ \\
High temperature treatment & $92.7 \% \pm 0.1 \%$ \\
Freeze-thawing treatment & $94.3 \% \pm 0.1 \%$ \\
Proteinase K treatment & $41.6 \% \pm 0.3 \%$ \\
Proteinase E treatment & $52.5 \% \pm 0.2 \%$ \\
Lipase treatment & $64.3 \% \pm 0.3 \%$ \\
Pectinase treatment & $94.1 \% \pm 0.1 \%$
\end{tabular}




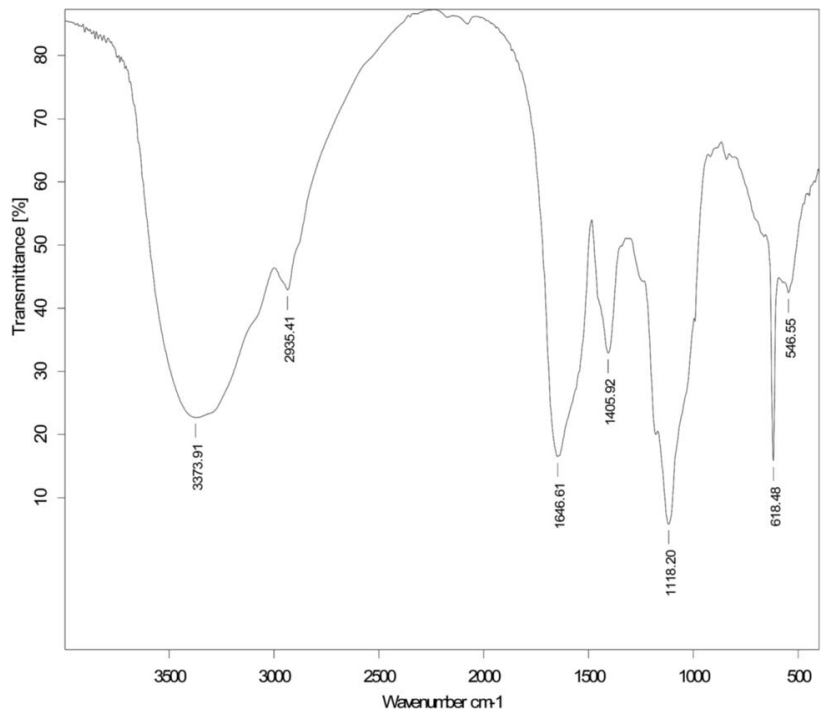

Fig. 5 FTIR spectra of the active components of the biodemulsifier for the W/O model emulsion.

a demulsification efficiency of $94.2 \%$ for the $\mathrm{W} / \mathrm{O}$ model emulsion after $24 \mathrm{~h}$. The TLC of the purified biodemulsifier, which was developed with chloroform-ethanol-water $(65: 25: 4)$ and treated with ninhydrin, revealed purple spots at $\mathrm{Rf}$ values of 0.59 for the $\mathrm{W} / \mathrm{O}$ model emulsion. In contrast, spots were not detected after staining with bromothymol blue or phenolsulfuric acid as color reagents. This suggests that the demulsifying components are lipopeptide substances. ${ }^{48}$ The FTIR spectra of the purified biodemulsifiers secreted by LH-1, as shown in Fig. 5, illustrate the structure of the biodemulsifier that broke the $\mathrm{W} / \mathrm{O}$ model emulsion. The adsorption peak at $3373 \mathrm{~cm}^{-1}$ is related to the stretching of an $\mathrm{NH}$ bond and indicates the presence of peptides, thus, the adsorption peaks appearing at $2935 \mathrm{~cm}^{-1}$ and $1405 \mathrm{~cm}^{-1}$, resulting from $\mathrm{C}-\mathrm{H}$ stretching, reflect the presence of an aliphatic chain. The stretching mode of the $\mathrm{CO}-\mathrm{H}$ bond and lactone carbonyl bond were observed at $1646 \mathrm{~cm}^{-1}$ and $1118 \mathrm{~cm}^{-1}$, respectively. In addition, the biodemulsifier that broke the $\mathrm{W} / \mathrm{O}$ model emulsion had a unique band at $618 \mathrm{~cm}^{-1}$, indicating the presence of additional $\mathrm{C}-\mathrm{H}$ bending vibration and a lactone. The previous results further indicate that the primary active components of the biodemulsifier for the W/O model emulsion were lipopeptide substances.

\subsection{The effect of the biodemulsifier produced by LH-1 on enhanced PHE solubilization}

The effect of the biodemulsifier produced by LH-1 on the solubility of PHE is shown in Fig. 6. The biodemulsifier markedly influenced the solubility of PHE. As the concentration of the biodemulsifier increased, the solubility of PHE tended to increase initially and then come to a steady state. The greatest PHE solubility was obtained at the concentration of $50 \mathrm{mg} \mathrm{L}^{-1}$, which indicated that the capacity of the biodemulsifier to entrap PAHs inside the micelle structure produced at $50 \mathrm{mg} \mathrm{L}^{-1}$ facilitated PHE solubilization. Thus, the higher concentrations

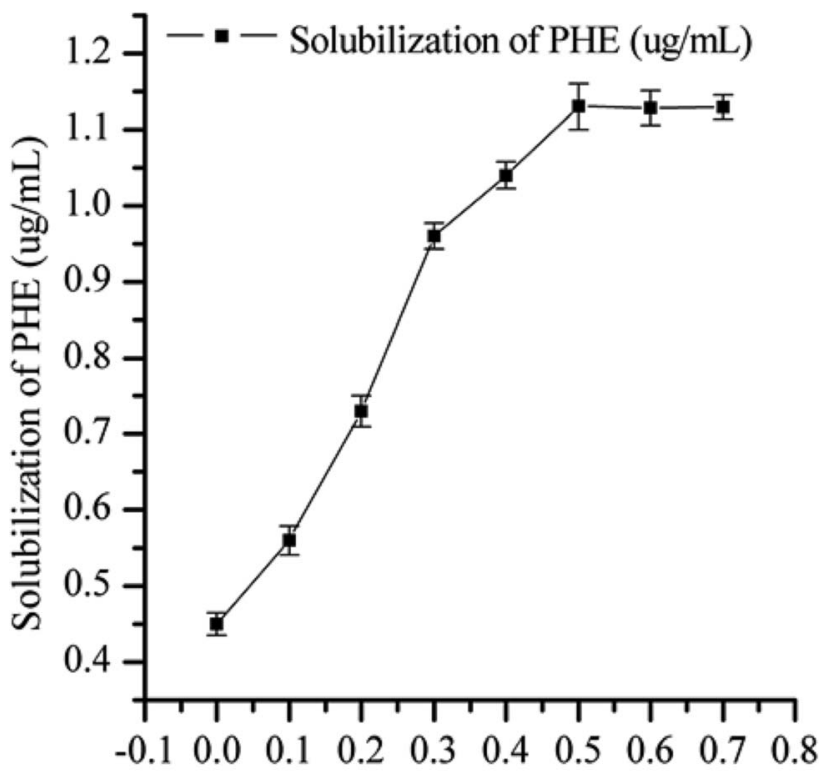

The biodemulsifier concentration $(\mathrm{mg} / \mathrm{mL})$

Fig. 6 Different concentrations of biodemulsifier solution efficiency on PHE solubilization. Each value is expressed as the average of triplicate observations, and the bars represent the standard deviation.

of biodemulsifier had no obvious influence on the solubility of PHE. Therefore, a moderate concentration of biodemulsifier is beneficial for enhancing the solubility of PHE. These results are useful in choosing the concentration in biodemulsifier enhanced remediation. Biodemulsifiers are amphiphilic compounds that contain both hydrophilic (head) and hydrophobic (tail) moieties. Biodemulsifiers have excellent surface activities and high demulsification efficiency. PHE, an insoluble compound, is hydrophobic and restricts bacterial uptake. The lipopeptide biodemulsifier produced by LH-1 is characterized by the ability to decrease the surface and interfacial tension at the surface and interface, therefore, this biodemulsifier is able to decrease the surface tension between the PHE and the water phase. The volume of the lipopeptide biodemulsifier gradually increased, leading to reduced interface membrane compactness and strength. It also formed micellar aggregates that incorporate hydrophobic compounds in the micelles, which consequently enabled the solubilization of PHE molecules into the water phase in the form of a complex, which is similar to the properties of biosurfactants. In the PHE bioremediation process, the major limitation of microbial degradation of PHE is its hydrophobicity. In this study, the biodemulsifier produced by LH-1 facilitated PHE solubilization, thereby smoothing the process of PHE degradation.

\section{Conclusion}

Biosurfactants have been studied for their ability to enhance the biodegradation efficiency of petroleum hydrocarbons in the environment, but little information was available on the influence of biodemulsifiers. Biodemulsifiers exhibit a high capacity 
for treating petroleum pollution because of their excellent surface activities and high demulsification efficiency. Thus, biodemulsifiers may be superior to normal biosurfactants for the treatment of insoluble petroleum hydrocarbons. In this study, it was determined that strain LH-1 can degrade the high concentration of aliphatic compounds and efficiently produce lipopeptide biodemulsifiers that can promote the solubility of the previously mentioned organic substances and improve the biodegradation of organic pollutants. Thus, the biotreatment of petroleum hydrocarbons using competent degraders of hydrocarbons such as LH-1 may be a useful ecofriendly strategy because it contributes to the minimization of process time and environmental impact. In addition, various common toxic pollutants (PHE, naphthrene, fluoranthene, pyrene, benzene, toluene and xylene) were utilized by strain LH-1 as the sole carbon source to produce biodemulsifiers, which indicate that strain LH-1 might be useful for large scale, cheap production and expanded applications. This is the first report of the ability of bacteria to degrade petroleum hydrocarbons and produce biodemulsifiers while using toxic environment pollutants as the sole carbon source.

\section{Acknowledgements}

This research was supported by the National Natural Science Foundation of China (Grant number 51408108).

\section{References}

1 X. F. Huang, W. Guan, J. Liu, L. J. Lu, J. C. Xu and Q. Zhou, Bioresour. Technol., 2010, 101, 317.

2 C. C. Lai, Y. C. Huang and W. Y. Hong, J. Hazard. Mater., 2010, 167, 607.

3 J. D. Desai and I. M. Banat, Microbiol. Mol. Biol. Rev., 1997, 61, 47.

4 S. Joshi, C. Bharucha, S. Jha, S. Yadav, A. Nerurkar and A. J. Desai, Bioresour. Technol., 2008, 99, 195.

5 A. Fiechter, Pure Appl. Chem., 1992, 64, 1739.

6 Y. Wen, H. Cheng, L. J. Lu, J. Liu, Y. Feng, W. Guan, Q. Zhou and X. F. Huang, Bioresour. Technol., 2010, 101, 8315.

7 N. Nadarajah, A. Singh and O. P. Ward, Process Biochem., 2002, 37, 1135.

8 J. Liu, X. F. Huang, L. J. Lu, J. C. Xu, Y. Wen, D. H. Yang and Q. Zhou, J. Hazard. Mater., 2010, 183, 466.

9 R. S. Makkar, S. S. Cameotra and I. M. Banat, AMB Express, 2011, 1, 5 .

10 Z. A. Raza, M. S. Khan and Z. M. Khalid, Process Biochem., 2007, 42, 686.

11 K. Dubey and A. Juwarkar, World J. Microbiol. Biotechnol., 2001, 17, 61.

12 K. S. Noah, S. L. Fox, D. F. Bruhn, D. N. Thompson and G. A. Bala, Appl. Biochem. Biotechnol., 2002, 98, 803.

13 Q. Z. Zhang, W. M. Cai and J. Wang, J. Environ. Sci., 2008, 20, 975.

14 M. V. P. Rocha, A. H. S. Oliveira, M. C. M. Souza and L. R. B. Goncalves, World J. Microbiol. Biotechnol., 2006, 22, 1295.
15 P. A. Felse, V. Shah, J. Chan, K. J. Rao and R. A. Gross, Enzyme Microb. Technol., 2007, 403, 16.

16 M. Nitschke, S. Costa, R. Haddad, L. A. G. Goncalves, M. N. Eberlin and J. Contiero, Biotechnol. Prog., 2005, 21, 1562.

17 R. D. Rufino, L. A. Sarubbo and G. M. Campos-Takaki, World J. Microbiol. Biotechnol., 2007, 23, 729.

18 I. M. Banat, R. S. Makkar and S. Cameotra, Appl. Microbiol. Biotechnol., 2000, 53, 495.

19 A. Shahi, S. Aydin, B. Ince and O. Ince, Ecotoxicol. Environ. Saf., 2016, 125, 153.

20 M. Dhote, A. Juwarkar, A. Kumar, G. S. Kanade and T. Chakrabarti, World J. Microbiol. Biotechnol., 2009, 263, 29. 21 A. Janbandhu and M. H. Fulekar, J. Hazard. Mater., 2011, 1873, 33.

22 J. B. Lanzon and D. G. Brown, Water Res., 2013, 47, 4612.

23 S. K. Satpute, A. G. Banpurkar, P. K. Dhakephalkar, I. M. Banat and B. A. Chopade, Crit. Rev. Biotechnol., 2010, 30, 127.

24 M. A. Heithcamp and C. E. Cerniglia, Appl. Environ. Microbiol., 1988, 54, 1612.

25 T. Avramova, A. Sotirova, D. Galabova and E. Karpenko, Int. Biodeterior. Biodegrad., 2008, 62, 415.

26 J. J. Xiao, L. J. Guo, S. P. Wang and Y. T. Lu, J. Hazard. Mater., 2010, 174, 818.

27 X. F. Huang, J. Liu, L. J. Lu, Y. Wen, J. C. Xu, D. H. Yang and Q. Zhou, Bioresour. Technol., 2009, 100, 1358.

28 J. C. Lee and K. Y. Lee, Biotechnol. Lett., 2000, 22, 1157.

29 N. Hou, F. Z. Feng, Y. Shi, H. M. Cao, C. Y. Li, Z. Cao and Y. Cheng, Environ. Sci. Pollut. Control Ser., 2014, 21, 10386.

30 A. Abdelhay, J. P. Magnin, N. Gondrexon, S. Baup and J. Willison, Appl. Microbiol. Biotechnol., 2008, 78, 881.

31 K. Peñuelas-Urquides, L. Villarreal-Treviño, B. Silva-Ramírez, L. Rivadeneyra-Espinoza, S. Said-Fernández and M. B. de León, Braz. J. Microbiol., 2013, 44, 1.

32 F. Bak, L. Bonnichsen, N. O. G. Jørgensen, M. H. Nicolaisen and O. Nybroe, Appl. Microbiol. Biotechnol., 2015, 99, 1475.

33 M. S. Kuyukina, I. B. Ivshina, J. C. Philp, N. Christofi, S. A. Dunbar and M. I. Ritchkova, J. Microbiol. Methods, 2001, 46, 149.

34 D. G. Cooper, C. R. Macdonald, S. J. Duff and N. Kosaric, Appl. Environ. Microbiol., 1981, 42, 408.

35 T. Barkay, S. Navon-Venezia, E. Z. Ron and E. Rosenberg, Appl. Environ. Microbiol., 1999, 65, 2697.

36 Z. Y. Ruan, S. Zhou, S. H. Jiang, L. Sun, Y. Zhai, Y. W. Wang, C. Chen and B. Zhao, Bioresour. Technol., 2013, 147, 477.

37 G. L. Wang, Y. J. Zhao, H. Gao, W. L. Yue, M. H. Xiong, F. Li, H. Zhang and W. Ge, Bioresour. Technol., 2013, 150, 259.

38 J. L. Song, J. G. Gu, Y. Zhai, W. Wu, H. S. Wang, Z. Y. Ruan, Y. H. Shi and Y. C. Yan, Bioresour. Technol., 2013, 140, 243.

39 X. Li, A. Li, C. Liu, J. X. Yang, F. Ma, N. Hou, Y. Xu and N. Q. Ren, Process Biochem., 2012, 47, 626.

40 H. Y. Xu, S. Y. Qi, Y. Li, Y. Zhao and J. W. Li, Environ. Sci. Pollut. Res., 2013, 20, 5762.

41 M. P. Pal, B. K. Vaidya, K. M. Besai, R. M. Joshi, S. N. Nene and B. D. Kulkarni, J. Microbiol. Biotechnol., 2009, 36, 747. 
42 J. Liu, X. Huang, L. J. Lu, J. Xu, Y. Wen, D. Yang and Q. Zhou, Bioresour. Technol., 2009, 100, 6481.

43 P. A. Felse, V. Shah, J. Chan, K. J. Rao and R. A. Gross, Enzyme Microb. Technol., 2007, 40, 316.

44 M. Benincasa, J. Contiero, M. A. Manresa and I. O. Moraes, J. Food Eng., 2002, 54, 283.

45 F. Li, L. Z. Zhu, L. W. Wang and Y. Zhan, Environ. Sci. Technol., 2015, 49, 3698.
46 M. P. C. Silvestre, R. L. Carreira, M. R. Silva, F. C. Corgosinho, M. R. P. Monteiro and H. A. Morais, Food Bioprocess Technol., 2012, 5, 1824.

47 P. Baindara, S. M. Mandal, N. Chawla, P. K. Singh, A. K. Pinnaka and S. Korpole, AMB Express, 2013, 3, 1.

48 S. C. Lee, S. J. Lee, S. H. Kim, I. H. Park, Y. S. Lee, S. Y. Chung and Y. L. Choi, Bioresour. Technol., 2008, 99, 2288. 